\title{
Top names at last
}

\section{Washington}

AFTER more than a year's vacancy in the top post at the US National Institutes of Health (NIH) and a protracted search for a new US National Science Foundation (NSF) director, the administration last week finally revealed its choices.

Bernadine Healy, a nationally known cardiologist, is to head NIH, and Walter Massey, vice-president for research at the University of Chicago and Argonne National Laboratory, will run NSF, assuming that there are no snags in the congressional confirmation process.

Healy has criticized NIH for underrepresenting women in clinical trials, paying too little attention to women's health issues and neglecting women researchers when selecting managers.

Massey, a physicist, is a member of the National Science Board and is vice president of the American Physical Society. $\mathrm{He}$ has recently taken a special interest in issues of technology transfer from research to industry. Christopher Anderson

HUBBLE SPACE TELESCOPE -

\section{Upside down rod}

\section{Washington}

AN investigative team assembled by the National Aeronautics and Space Administration (NASA) to find the cause of the Hubble Space Telescope's optical distortions last week fingered the culprit.

A measuring instrument known as a metering rod may have been used upside down, aggravating a separate problem in which reflections from a cap placed at the end of the rod sent false signals that confused the technicians shaping the mirror, the team said.

"Aspects of th[is] scenario have been reproduced with an interferometer and metering bar/end cap simulations, and the end results indicate that the scenario as described is probable", team leader Lew Allen, director of the Jet Propulsion Laboratory, said in a statement.

The metering rod is used to set precisely the distance between elements of an optical device known as a null corrector that was used to help shape Hubble's main mirror. A $1.3 \mathrm{~mm}$ error appears to have arisen when technicians fitted an end cap with a pinhole at a position $1.3 \mathrm{~mm}$ beyond the end of the solid metering rod, to ensure that the reference beam was reflected off the very centre of the rod's end. However, the end cap was itself shiny and the light beam seems to have been reflected off the cap, rather than travelling through the pinhole.

The fact that the metering bar seems to have been used upside down, with its intended reflective end away from the light beam, only made the situation worse.

Christopher Anderson

\section{Japan gets its act together}

\section{Tokyo}

THE Japanese government is at last trying to put together into one coordinated whole its various efforts to contribute to international plans to sequence the human genome. Alongside an expansion in funding for genome-related research, the Council of Science and Technology, Japan's principal science policy-making body, will try this week to harmonize the competing activities of various government ministries and agencies.

Japan's financial commitment to research on the human genome has so iar been small, and has provoked complaints from James Watson, director of the US National Institutes of Health Center for Genome Research (see Nature 342, 463; 1989). Budget increases now under way will still leave Japan with a small contribution in relation to its gross national product, but nevertheless represents a small victory for Japanese scientists.

The Ministry of Education, Science and Culture (MESC) is to boost funding for grants from $¥ 280$ million to $¥ 500$ million (\$3.6 million) per year, following the completion of a two-year preparatory study put together by Kenichi Matsubara of Osaka University. The ministry has also requested $¥ 850$ million (\$6.2 million) over five years to establish a new Genome Analysis Centre at the Institute of Medical Science at Tokyo University. But the centre, which MESC hopes eventually will have a staff of about 20 people, still faces a difficult future because of the freeze on the appointment of new government employees. MESC's plans for the centre are in fact extremely ambitious, as the $¥ 850$ million is only the beginning of a much larger expenditure, and MESC wants to supplement the activities with new posts at universities throughout Japan.

A further problem, according to Matsubara, may be a conflict with the Science and Technology Agency (STA)'s plans to support related work at the Institute of Physical and Chemical Research (RIKEN). Masato Chijiya, director of STA's Life Science Division, says that such an overlap is one of things that will have to be sorted out by the Council of Science and Technology and a committee of ten scientists headed by Wataru Mori, former president of Tokyo University, that will be appointed by the council on 21 September.

STA plans to expand its budget only slightly - by about $¥ 100$ million ( $\$ 1$ million) - for genome-related research next year. A total of $¥ 542$ million ( $\$ 4$ million) has been requested for RIKEN, of which $¥ 303$ million will go towards deveiopment of automatic DNA sequencing machines and to DNA sequencing.
The remainder goes to a gene bank which is already under development at RIKEN's Life Science Centre in Tsukuba.

Other ministries are also climbing aboard the genome bandwagon. The Ministry of Health and Welfare is requesting $¥ 400$ million, up from $¥ 200$ million this year, for a project to analyse and sequence oncogenes. And the Ministry of Agriculture, Forestry and Fisheries is requesting $¥ 610$ million for fiscal year 1991 to begin sequencing the rice genome. For this project, which is expected to last seven years, $¥ 155$ million is allocated to DNA sequencing and research to be carried out largely at the ministry's National Institute of Agrobiological Resources in Tsukuba, $¥ 326$ million is for mapping that will be farmed out to private companies, $¥ 100$ million is for equipment and facilities, and $¥ 16$ million will go to study of the establishment of yet another DNA bank.

Still to join the fray is the powerful Ministry of International Trade and Industry (MITI). Michio Oishi of Tokyo University is trying to win support from MITI and private industry. Japanese companies do not see much of market in the human genome project itself but are interested in the possibility of developing diagnostic machines for the medical market, Oishi says. It will probably be some time before MITI makes a move but if it dces, Oishi is confident that its budget will be larger than that of other ministries.

All of the budget requests are subject to negotiation with the Ministry of Finance but they are unlikely to undergo drastic change. If granted in full, Japan's total government budget for human genome research will still be less than a quarter that of the United States (but well above that of many European countries).

Despite the extra money, Matsubara sees no sign of Japanese funds for the Human Genome Organization (HUGO), which will coordinate the international research effort. The Wellcome Trust in the United Kingdom and the Howard Hughes Foundation in the United States have contributed more than a million dollars to HUGO and one of Watson's main criticisms was directed at Japan's failure to contribute to that organization.

Very restrictive laws on the establishment of foundations in Japan are effectively blocking Japan's ability to contribute to HUGO, according to Matsubara. To establish a foundation, $¥ 200-¥ 300$ million ( $\$ 1.5-\$ 2.2$ million) must first be raised, which actually means raising twice as much because donations initially are not tax free. Then the foundation must operate for several years before it can win tax-free status.

\section{David Swinbanks}

